\title{
Violencia política y electoral en las elecciones de $2018^{*}$
}

\section{Political and Electoral Violence in the 2018 Elections}

\author{
ARTURO ALVARADO MENDOZA**
}

\begin{abstract}
This exploratory work aims to show how political and electoral violence manifested themselves during Mexico's 2018 elections and casts light on their consequences. With a data base designed to delve into the new forms of electoral and political violence that surged from political competition, polarization among conflicting groups, and criminal organizations' interventions in Mexico's electoral processes, this article takes on a systematic literature review. Among its hypotheses, this work proposes that electoral competition generates political violence, while probing into its causes. This work concludes, among other findings, that democratization has not served as a buffer to violence.
\end{abstract}

Key words: organized crime, corruption, standards of democracy, electoral integrity, democratic erosion, Mexico

\begin{abstract}
Resumen
Este artículo es un trabajo exploratorio cuyo objetivo es mostrar cómo se manifestó y qué consecuencias produjo la violencia política y electoral en los comicios de 2018. $\mathrm{Su}$ diseño se sustenta en la construcción de una base de datos empleada para profundizar en nuevas modalidades de violencia electoral y política en México, producidas por la competencia política, la polarización entre grupos en contienda y por la intervención de organizaciones criminales en los procesos electorales. El artículo revisa sistemáticamente la literatura. Entre sus hipótesis propone que la competencia electoral genera la violencia política, e indaga sobre las causas de ésta. Una de sus conclusiones es que la democratización no ha detenido la violencia.
\end{abstract}

Palabras clave: crimen organizado, corrupción, calidad de la democracia, integridad electoral, erosión de la democracia, México

\section{La democracia, las elecciones y la violencia}

$\mathrm{E}^{1}$ 1 proceso electoral mexicano de 2018 puso de manifiesto la combinación de tres fenómenos nuevos en el panorama político, así como un problema emergente en la literatura sobre la democracia. Frente al contundente triunfo de un candidato a la Presidencia de la República, que con amplia legitimidad no ocurría en el país desde hace más de tres décadas, los comicios estuvieron plagados de actos de violencia e ilícitos de mayor magnitud, si los comparamos con cada una de las elecciones desde la alternancia política del año 2000. Junto con estos actos delictivos hay evidencia suficiente de que varios actores y organizaciones criminales están

\footnotetext{
* Artículo recibido el 05/10/18 y aceptado el 12/02/19.

** El Colegio de México, Centro de Estudios Sociológicos. Carr. Picacho Ajusco 20, col. Fuentes del Pedregal, 14110 , Ciudad de México <alvarado@colmex.mx>. orciD: https://orcid.org/0000-0002-6922-3507.
} 
interviniendo en los procesos electorales, ya sea sobre los candidatos, en las campañas o sobre la voluntad ciudadana. Este fenómeno se acompañó también de la emergencia de un nuevo partido político, lo cual contrasta con la crisis de los partidos nacionales y la fragmentación del voto. Este proceso parece ir a contracorriente de los sucesos electorales del subcontinente latinoamericano, pero, además, revela un problema que la literatura busca explicar: el ejercicio de la violencia en y durante los comicios, con el propósito de influir, alterar o consolidar ciertas tendencias y fuerzas políticas. El presente trabajo explora la problemática de la nueva violencia político-electoral, a la luz del examen de las votaciones de 2018.

En años recientes se ha revitalizado la discusión acerca del impacto que tiene la violencia en los procesos políticos y en las elecciones; el problema está compuesto por varios sucesos emergentes, entre ellos tres: i) un incremento del uso de los recursos ilícitos y violentos en procesos electorales, ii) una abundante evidencia de nuevas modalidades de violencia política estatal, no limitada a la intimidación, coacción o represión en contra de los ciudadanos, sino que presenta otras formas complejas del uso de recursos públicos, de corrupción y algunas formas de coerción del voto, y iii) la documentación, por parte de autoridades y expertos, sobre intervenciones de algunas organizaciones criminales en los comicios, en la formación de gobiernos o en la cooptación de las élites en el gobierno. Estos fenómenos incluyen varias estrategias de corrupción durante los comicios, que han sido acciones estratégicas de actores internos de las coaliciones en el poder para apropiarse de los recursos públicos o capturar agencias estatales. Estas acciones contra la democracia, algunas de las cuales han resultado en grandes escándalos, son protagonizadas por autoridades públicas, pero también por corporaciones de empresas privadas locales o internacionales, así como por organizaciones que operan al margen de la ley. Son actos predatorios de la gobernanza y contra la integridad electoral. El problema es que, mientras estas actividades ilegales producen un claro daño a la democracia, los gobiernos que las provocan no son procesados y muchos continúan en el poder. El escán- dalo más reciente producido por la empresa Odebrecht ha desencadenado una de las crisis más profundas de los gobiernos latinoamericanos. ${ }^{1}$ Los políticos y sus partidos han encontrado vías para evadir la justicia, gobernar y mantener la obediencia de los súbditos. Todo esto ha tenido como consecuencia la formación de gobiernos débiles, ilegítimos, irresponsables. Las elecciones, en este sentido, son un escenario y un momento particular en donde aparecen incentivos para transgredir el orden público y democrático. El presente trabajo busca algunas explicaciones de estas conductas, sus modalidades y sus repercusiones.

Casos notorios de violencia política durante procesos electorales en México han ocurrido en el siglo xx, pero también durante la transición política y en los años posteriores a la alternancia presidencial. ${ }^{2}$ Desde entonces se han producido asesinatos que han complicado las elecciones y la integración de gobiernos. Recordemos el asesinato del candidato del Partido Revolucionario Institucional (PRI) a la Presidencia de la República en 1994 o, en otra escala y momento, el del aspirante del PRI a la gubernatura de Tamaulipas, Rodolfo Torre Cantú, el 28 de junio de 2010. A partir de entonces hemos registrado numerosos homicidios, secuestros, amenazas y otros actos ilícitos contra candidatos a todos los puestos electivos, y aquí hacemos un recuento de los mismos.

Esto no es único de México. Podemos anotar que esta violencia política y electoral se experimenta en Colombia (la parapolítica) o en Guatemala o El Salvador y en muchas ocasiones también el fraude y la simulación en las elecciones sigue siendo práctica de gobiernos autocráticos, como Venezuela o Nicaragua. Otras veces parece ser obligatorio negociar con actores delincuenciales que dominan territorios y grupos de electores; así lo probó lo acontecido en El Salvador entre 2016 y 2019, en donde la prensa documentó que los partidos en la contienda presidencial y sus candidatos negociaron con secciones de dirigentes de la Mara Salvatrucha para que les permitieran realizar campañas o implementar programas públicos urbanos en los territorios que ésta mantiene bajo su influencia. Se conoce que esta pandilla controla grupos de electores y determina cómo votan (González, 2019).

\footnotetext{
1 Aun cuando no es el único caso, el Lava Jato generado entre actores del gobierno y la empresa de origen brasileño Odebrecht (entre otras) desató la mayor crisis política en décadas en la región, empezando con Brasil; pero luego aparecieron acusaciones por financiamiento electoral ilegal en Colombia, Perú, Ecuador, El Salvador, Argentina y México. El escándalo ha llevado a persecuciones judiciales y políticas, a la destitución y hasta al encarcelamiento de presidentes, miembros y líderes de los poderes legislativos y judiciales, como atestiguamos en Brasil y Perú. Procesos similares ocurrieron en Colombia con la "parapolítica", que resulta ejemplar para entender lo que se está viviendo en México (Romero, 2007: 321).

2 Sería de esperarse que la violencia hubiera aumentado en México en años siguientes a la alternancia política del año 2000 y debería haber disminuido en comicios posteriores, pero ha ocurrido lo contrario. Podría argumentarse que la violencia electoral es parte de la inestabilidad política durante procesos de transición o democratización de regímenes autoritarios o un instrumento de estos regímenes para imponer sus metas.
} 
Las definiciones clásicas no contemplan que los actores del gobierno pueden estar involucrados en actos ilegales, o que fuerzas coercitivas no estatales ejerzan la represión contra ciudadanos y grupos partidistas, y que lo hagan mediante la manipulación de recursos públicos o utilizando agentes políticos, policías o grupos criminales para coaccionar a los votantes. Es necesario explorar nuevas explicaciones. ${ }^{3}$

Los procesos electorales en México han sido escenario de conflictos que han limitado la legitimidad de los gobiernos y afectado su representatividad y efectividad. Los conflictos en las elecciones han sido el motor de cambio político aun después de la alternancia en la Presidencia de la República en el año 2000. Desde entonces, si bien tenemos avances en las normas, en las instituciones y en las reglas de la competencia, varios procesos han conservado irregularidades, a las que se agregan un ambiente de polarización, campañas cargadas de grandes expectativas de cambio, con claros reclamos por acusaciones de fraude que han llevado a disputas poselectorales violentas. Este contexto se suma a un periodo en el que la violencia criminal se ha extendido prácticamente a todo el territorio mexicano y ha producido una crisis de seguridad generalizada, en donde, además, delincuentes influyen en los electores y los gobernantes. La excepcional y amplia victoria de un candidato en la elección presidencial de 2018 ocultó muchos de los conflictos y de las actividades ilícitas que prevalecieron en el panorama electoral, como lo mostraremos en este trabajo. Este doble fenómeno de un incontestable triunfo de la oposición y una creciente violencia electoral caracteriza las votaciones de 2018.

A lo largo de la historia electoral mexicana se ha vulnerado con violencia la integridad electoral, entre otros con los fraudes electorales cometidos tanto por partidos políticos como por el propio gobierno (Molinar, 1991; Sonnleitner, Alvarado y Sánchez, 2013), o con el uso de recursos gubernamentales de manera ilícita, piénsese en las tarjetas "monex", o con financiamiento ilegal a un candidato y a un grupo de aliados (los Amigos de Fox; el Pemexgate). Algunos actos de corrupción en los procesos electorales no generan automáticamente consecuencias jurídicas, no obstante, producen daños institucionales y a la legitimidad de los gobiernos. ${ }^{4}$

Las concepciones clásicas sobre este comportamiento han entendido por violencia política aquella que es ejercida por el Estado o por las élites políticas contra los ciudadanos o los grupos opositores (Moore, 1996; Arendt, 1970; Schmitt, 1982; Moreno, 2009). Esta idea centra el ejercicio de la violencia en la relación entre gobernantes y gobernados, pero actualmente es necesario ampliar los atributos del concepto a otros hechos como son los conflictos entre grupos en el gobierno, entre agrupaciones partidistas, o entre distintas organizaciones criminales que buscan controlar a candidatos y gobiernos.

Si la democracia es un sistema en el cual se regula la violencia legal y legítima y se castiga la ilícita y no legítima, el régimen mexicano enfrenta una formidable tarea para consolidarse. Esto nos muestra que los comicios son escenarios propicios para acciones ilegales que requieren explicaciones más allá de la legitimidad y representatividad política y de las interpretaciones clásicas.

Frente a la bibliografía clásica hay nuevas corrientes que intentan dilucidar la violencia política (VP), y más específicamente la violencia electoral (VE). La literatura comprende temas como las normas, los incentivos, los instrumentos, lo que está en juego o la integridad de los procesos. No es concluyente respecto de ninguno, pero se concentra en los incentivos y en los instrumentos de las agresiones. La violencia se produce cuando existen incentivos para cometer las agresiones, teniendo en cuenta tanto la capacidad de respuesta de los opositores, como las acciones de las autoridades y las normas que rigen los procesos. A esto se suman la calidad de las elecciones y la integridad electoral (Derrick, 2009; Mochtak, 2018; Wilkinson, 2004; Nieburg, 1969; Martínez I Coma, Norris y Frank, 2015), que muestran las distintas formas y retos que tienen los ciudadanos para construir procesos electorales limpios, en los cuales el sufragio sea respetado y las autoridades resulten electas en un proceso legal

3 Según Amalia Pulido, las organizaciones criminales intentan controlar a los políticos y gobernantes para protegerse; su relación con los partidos políticos tendría el propósito de reducir la incertidumbre sobre sus actividades, asegurar su protección por parte del Estado (2017: 16) e influir en sus decisiones. Los medios más usuales de incidencia han sido corromper autoridades, amenazar o asesinar candidatos que rechacen las preferencias de los líderes de organizaciones criminales, o intimidar a los votantes para desincentivar la competencia o fortalecer alternativas electorales con preferencias más cercanas a las de dichas organizaciones (Ponce, 2014 y 2018).

4 El Instituto Federal Electoral (IFE) difundió que entre diciembre de 1999 y julio de 2000, Vicente Fox Quesada (entonces precandidato a la Presidencia de la República) recibió 345000 pesos por parte de la organización Amigos de Fox conformada por empresarios y personajes ajenos al medio político, con la finalidad de que dicho candidato ganara las elecciones. A pesar de que la institución tuvo la documentación probatoria, no se ejecutaron acciones penales en ese momento (Garduño y Román, 2003). Años después de que terminara la administración de Fox el Instituto reconoció el ilícito, pero el daño quedó impune. 
y legítimo. ${ }^{5}$ Todo régimen tiene formas de organizar y utilizar la violencia, la democracia es un modo de instaurarla, regularla y limitarla de manera legítima estableciendo reglas para el ejercicio de la libertad, la igualdad y la justicia (North, Wallis y Wingast, 2009). Para asegurar la funcionalidad de la democracia se requieren normas claras y equitativas y organismos (que acaten las leyes) facultados expresamente para garantizar el sufragio efectivo.

Varias preguntas guían el estudio de la violencia política y la electoral: ¿Cómo se producen estos eventos? ¿Cuáles son sus causas probables? ¿Acaso tiene que ver con incentivos asociados con las normas y con la fortaleza o debilidad de las instituciones electorales (con impunidad)? ¿Cómo influye, o qué papel tiene, la fortaleza o debilidad de las instituciones electorales en la ve? ¿En qué sentido influye lo que "está en juego”? ¿Está asociada a niveles de competencia o conflicto? ¿Puede producirse por la fragmentación del poder? ¿Quiénes son los generadores de la vP y la vE, la autoridad o agentes externos (organizaciones criminales)?

El contexto criminal puede reducir o limitar las opciones de la competencia electoral. Pero la ve no sólo se asocia con la presencia de la delincuencia organizada, antes bien, puede tener relación con disputas en el interior de y entre partidos, así como con pugnas diversas entre élites regionales por el control político, económico o territorial de algunos puestos electorales.

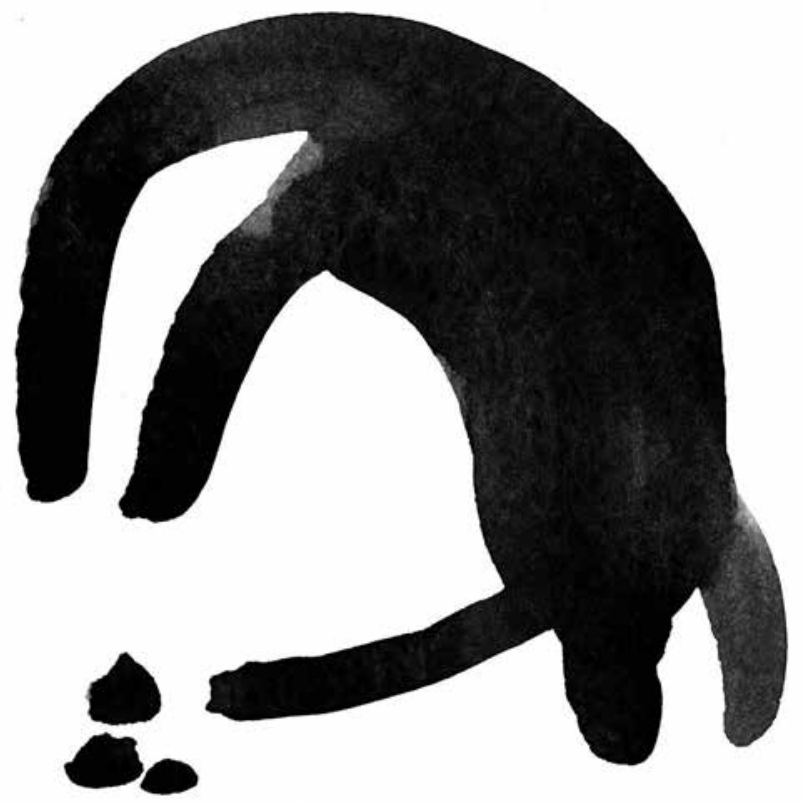

En ocasiones la vE está sustentada en incentivos electorales en distintas escalas y en las estrategias de las autoridades para impedirla o abstenerse. Es importante notar la inmensa impunidad con que se realizan los actos ilícitos, entre otras cosas por la debilidad de las instituciones electorales o las diferencias entre ellas (por ejemplo, la Fiscalía Especializada para la Atención de Delitos Electorales [FEPADE] ha demostrado ser incapaz de resolver la gran mayoría de casos y demandas, pero también el Tribunal Electoral del Poder Judicial de la Federación [TEPJF] ha tomado decisiones contradictorias sobre conflictos $\mathrm{y}$ actos violatorios a las leyes electorales).

Otros trabajos analizan el papel de las autoridades, locales o estatales, y sus estrategias de competencia por el poder, que generan motivaciones para incurrir en actos violentos. Algunos más examinan las normas y la debilidad de las instituciones electorales frente a los conflictos (incluso podría argumentarse que ciertos conflictos surgen por las conductas de las autoridades electorales). Aquí se indagarán las siguientes cuestiones a manera de hipótesis: 1) La competencia entre partidos y candidatos genera la vE. 2) La escala y el cargo o "puesto" en competencia (su jerarquía local o federal) explica la vE. 3) Asimismo, se explorará cómo se reflejan en la ve los conflictos locales -entre grupos políticos más allá de los partidos-o la polarización entre estos grupos. En particular, una combinación entre la afiliación partidaria y el cambio de ésta podría ser fuente de disputas por el poder local o en el interior de los organismos políticos. Al parecer la violencia homicida se dirige de un modo particular cuando las víctimas son de la oposición. Y la afiliación partidaria también puede combinarse con problemas dentro de los organismos políticos (o entre la élite local). 4) La última hipótesis es si la presencia de criminales genera la ve (y parcialmente la vp).

La creciente situación criminal en México acompaña las elecciones locales y nacionales, con mayor evidencia desde 2006. Son fenómenos simultáneos y nosotros indagaremos sobre sus posibles influencias. Desde la década pasada ya se había incrementado el asesinato de autoridades y de candidatos a puestos de elección popular. Por tal motivo mostraremos de manera sintética la evolución de estos eventos en las elecciones locales y federales entre 2012 y 2018 , para luego concentrarnos con más detalle en los comicios de 2018 .

5 La literatura sobre integridad electoral incluye varias dimensiones y momentos que vulneran la democracia, desde el registro de los votantes, pasando por el respeto a las normas (que consideran, hoy día, son universales), así como los procedimientos de las campañas y los del día de los comicios (Martínez I Coma, Norris y Frank, 2015: 39-40). 


\section{Violencia electoral y política, definiciones y propuesta}

Entendemos por violencia electoral una conducta de agresión que amenaza en general al régimen político y al democrático, y que se manifiesta a través de comportamientos destructores de los procesos electorales (Derrick, 2009: 9). Una definición similar está en el documento de trabajo de la International Foundation for Electoral Systems (IFEs), la cual indica que puede tratarse de actos aleatorios $u$ organizados que pretenden intimidar, dañar físicamente, destruir la propiedad pública o la privada, u otra acción que influya en el proceso electoral (Fischer, 2002: 8). En estas acciones deben incluirse asesinatos, asaltos, incendios provocados, saqueos, daño o destrucción de la propiedad privada, secuestros, amenazas, asalto sexual, invasión de las oficinas de los competidores, entre otras (Derrick, 2009: 9). Es importante agregar los ataques verbales o escritos en distintas formas (como las virtuales) y remarcar que algunas conductas son violencia política basada en el género. Es un vasto repertorio de comportamientos individuales o colectivos encaminados a provocar un daño y que se ponen en acción en un contexto y tiempo electorales. El conflicto y la violencia son mecanismos de intervención para destruir un proceso legal y legítimo.

Los propósitos con los que se ejerce esta agresión pueden abarcar desde: 1) ganar las elecciones con actos ilegales; 2) influir en los procesos para que pierda la competencia; 3) violar las leyes electorales para obtener beneficios en votos, recursos o puestos; 4) cooptar, intimidar o capturar a los candidatos y gobernantes para que efectúen o permitan el ejercicio de actividades ilícitas; 5) adquirir puestos gubernamentales para beneficio ilegítimo de alguna persona o grupo; 6) capturar el Estado; y 7) controlar a los ciudadanos.

Existen varias alternativas para clasificar la vE, a partir de las estrategias y propósitos de los actores o por la escala en donde es ejercida. Por ejemplo, algunos conflictos pueden surgir por las acciones de electores no conformes con los comicios y sus resultados; a veces el motivo se genera desde el Estado; otros casos están centrados en las controversias entre competidores, candidatos o partidos; y otros más están asociados con protestas mayores (como de gremios de maestros o de comunidades indígenas), que se combinan con los comicios. En ciertas ocasiones son provocados por disputas territoriales o étnicas y, con menor frecuencia, por enfrentamientos ideológicos como aquellos entre grupos guerrilleros (característicos de algunos países de la región y de México).

En suma, la violencia electoral forma parte de la violencia política, pero se distingue de ella porque se localiza dentro de un contexto electoral en el que distintos actores y la sociedad civil compiten por obtener una cierta cantidad de cargos y recursos públicos; porque su motivación e instrumentos son precisamente electorales. Una concepción amplia de la vp que incluya la ve debe tener en cuenta que: 1) puede ser ejercida por actores estatales y no estatales; entre ellos, las élites políticas locales son centrales en este juego político y su manejo de los recursos públicos y coercitivos; 2) es posible clasificarla en formas interpersonales o colectivas; 3 ) tiene destinatarios, principalmente autoridades o instituciones públicas (aunque puede estar dirigida contra los ciudadanos); y 4) pretende alterar su constitución, capacidad representativa, funcionamiento o capturar los bienes públicos para beneficio privado, además de alterar las políticas públicas. La vP puede ser empleada durante las elecciones, pero también en otros periodos. No obstante, el vínculo entre vP y elecciones provoca cuestionamientos acerca de sus efectos en los procesos democráticos. La vP incluye el uso de la fuerza física y/o psicológica utilizada “con el propósito de modificar el comportamiento de los actores" (Nieburg, 1969) de manera legal, ilícita o ilegítima, así como para alterar los resultados electorales o la integración de los gobiernos, de forma tal que producen un daño a los competidores, a las instituciones públicas y a la democracia. Asociados con la ve se encuentran los actos que constituyen delitos electorales sancionados por la legislación; ${ }^{6}$ estas transgresiones, si bien pueden no ser violentas, influyen en los resultados de los comicios.

Esta definición incluye la clasificación de los actores, sus actividades, el ciclo temporal, los motivos o propósitos y los “objetos" de la disputa (Mochtak, 2018: 27). La violencia perturba el ciclo electoral y sus resultados y se distingue de otros actos criminales por su relación directa con eventos, personalidades y temas específicamente vinculados con los comicios, y tiene un impacto específico durante el ciclo de las campañas electorales (Wassermann y Jaggard, 2007 cit. en Mochtak, 2018: 28; Martínez I Coma, Norris y Frank, 2015). La violencia es un instrumento que pueden utilizar quienes ostentan el poder (ganadores), quienes los retan, los perdedores y otros actores externos al juego político formal y con capacidad y

6 Véase Ley General en Materia de Delitos Electorales (LGMDE) de 2014 (Diario Oficial de la Federación, 23 de mayo de 2014 ). 
con recursos para influir. El propósito es, también, truncar ciertas candidaturas o fuerzas partidarias. Así, se daña la confianza, la legitimidad y la integración de gobiernos. Es importante identificar cuál es el "objetivo" del ataque: una persona, una autoridad, un candidato, una casilla, una oficina de gobierno, familiares, miembros de partidos, propiedades. Pero, en un plano más general, su finalidad es alterar las condiciones de la competencia.

Es factible medir la violencia, ya sea con escalas o niveles que abarquen desde incidentes sin grandes consecuencias, amenazas incumplidas a candidatos en campañas, disrupción en unas cuantas casillas aisladas, disturbios violentos pero localizados (robo de casillas menor a un porcentaje legalmente sancionable), hasta revueltas o rebeliones en donde se toman casillas, se destruye documentación, se secuestra a autoridades, se toman oficinas públicas como los ayuntamientos o se asesina a algún candidato. En ocasiones, la estrategia combina varias prácticas. Las elecciones para gobernador en Puebla en 2018 estuvieron marcadas por varios de estos hechos.

\section{Estrategia, método y datos del presente artículo}

El artículo es una exploración sistemática de los eventos de 2018 que consignamos de acuerdo con las definiciones. Es un trabajo exploratorio y comparativo con el fin de probar las hipótesis enunciadas. Para llevar a cabo este estudio se construyó una base de datos sobre actos de violencia sucedidos en procesos electorales a partir de 2012 y luego se integró una sección para inscribir los eventos ocurridos durante el calendario electoral oficial de las elecciones de 2018 . Se construyeron dos series de códigos: primero, clasificamos los actos que definimos como ve, observados y reportados durante el periodo electoral; y, segundo, registramos lo que (de acuerdo con la LGMDE citada) se define como delitos electorales.

En esta entrega sólo mostramos el primer conjunto de eventos de vE. Es pertinente aclarar que las definiciones de los eventos, así como las reglas de clasificación que diseñamos, difieren de otros trabajos, porque construimos varias condiciones para incluir los hechos delictivos y excluimos muchos casos que se suscitaron durante los comicios, pero no son estrictamente actos que incidan en las elecciones (por ejemplo, los homicidos de policías y otras autoridades de seguridad, aun cuando tengan una clara motivación política).

Las categorías empleadas son asesinato; robo (de materiales electorales); amenazas verbales o escritas; secuestro o extorsión de candidatos o funcionarios o sus familiares; vandalismo contra la propaganda, contra candidatos o funcionarios electorales y contra oficinas o propiedades de partidos durante actos de campaña. Para 2018 agregamos las categorías "agresiones" y "extorsiones" como nuevas variables de las que no había datos previos, pero el resultado fue poco revelador. También añadimos agresiones contra mujeres. Las categorías que corresponden a los delitos electorales fueron elaboradas, en parte, con base en la LGMDE y son: sufragio ilegal; compra de voto o coacción al votante; interferir u obstaculizar el desarrollo de las elecciones; usurpar o no cumplir funciones legales; falsificar, alterar o apoderarse de documentación o materiales electorales; divulgar información electoral falsa o de manera ilegal; uso ilegal de recursos; acarreo de votantes; proselitismo en circunstancias o periodos prohibidos; corrupción y clientelismo. Los datos entre 2012 y 2016 son el resultado de la compilación de distintas fuentes estadísticas oficiales, notas de prensa, análisis de reportes públicos y artículos en revistas especializadas. La lista de hechos delictivos comprende 96 municipios en 28 entidades de la federación, incluye reportes de las instituciones electorales. Los registros no son compatibles con otras fuentes públicas o publicaciones. ${ }^{7}$

Es pertinente mencionar que en las definiciones de las categorías sí tomamos en cuenta actos de vE ocurridos fuera de los ciclos de las campañas, esto es, antes y después de los comicios. Pero no consideramos aquellos actos de vP que se llevan a cabo dentro de las campañas, mas no tienen un motivo en y

\footnotetext{
7 Las fuentes no siempre son claras respecto al hecho delictivo, las víctimas, o ambos. A veces hay imprecisiones sobre la localización de los hechos y, en la gran mayoría, no es posible discernir las causas del crimen y éstas no son concluyentes. Parte del problema de verificación consiste en que este tipo de intimidaciones permanecen ocultas. Los delincuentes y los políticos involucrados en los procesos electorales tienen interés mutuo en esconder los hechos y, en ocasiones, la autoridad electoral es incapaz de conocerlos. Adicionalmente, cuando el proceso electoral está en curso, sólo se conocen rumores de intervención de grupos criminales, y tiempo después se descubre que la candidatura estuvo ligada a cierto grupo ilegal desde sus inicios, con un gran daño al proceso y a los ciudadanos (Guerrero, 2014: 1). También sucede que las autoridades utilizan recursos públicos para favorecer a sus partidos y a ciertos candidatos así como para incentivar votantes. Un ejemplo se verificó en la delegación Coyoacán, donde la autoridad electoral registró la distribución de bienes a los electores (como tinacos), así como pintas de lugares públicos o privados con colores del Partido de la Revolución Democrática (PRD) (Gutiérrez, 2018).
} 
desde las mismas (por ejemplo, homicidios de policías o asesinatos de ciudadanos), porque no conllevan un componente electoral o un impacto directo en el proceso electoral. Si bien los hechos reportados se efectuaron dentro del periodo electoral, es difícil postular inferencias sólidas respecto de muchas agresiones a funcionarios, exfuncionarios y ciudadanos en general, y asociarlas al momento electoral, dado que incluso cuando son concurrentes, no necesariamente tienen una conexión causal.

El cuadro 1 ofrece una síntesis de las actividades ilícitas que se realizan en los procesos electorales, los actores que las emplean y a quiénes están dirigidas.

Con base en los códigos recopilamos y agrupamos las notas de prensa desde 2012 hasta 2018. La temporada electoral 2018 comprende del mes de octubre de 2017 al 4 de julio de 2018, así como los meses posteriores cuando se revisaron las controversias y los ganadores tomaron posesión y crearon gobiernos, hasta el mes de diciembre. Una de las revisiones que tomó más tiempo fue la de las elecciones de gobernador del estado de Puebla, donde, si se compara con otras entidades, hubo un mayor registro de actos delictivos. La información fue clasificada y almacenada en una base de datos con la fecha del hecho violento o delito electoral, la entidad federativa donde ocurrió, el municipio y la localidad (cuando había información disponible), el agresor o denunciado, la víctima o denunciante, así como su cargo de responsabilidad o afiliación política o partidista. La base de datos es el sustento de este artículo.

Consignamos eventos que podrían ser violentos, pero que requieren más análisis porque no "encajan" en la definición limitada que formulamos. Algunos de ellos pueden referirse a casos de simulación, es decir, a conductas que pretenden utilizar o manipular las normas legales para registrarse; un ejemplo de esto ocurrió en Oaxaca donde, mediante el recurso de

Cuadro 1

Violencia política y actividades violentas e ilegales en los procesos electorales

\begin{tabular}{|c|c|c|c|}
\hline \multirow{6}{*}{$\begin{array}{l}\text { Violencia } \\
\text { política } \\
\text { y en el } \\
\text { proceso } \\
\text { electoral }\end{array}$} & \multirow{4}{*}{$\begin{array}{l}\text { Acciones directamente } \\
\text { violentas } \\
\text { (Amenazas, asesinato, } \\
\text { robo, secuestro, agresiones, } \\
\text { extorsión, vandalismo) }\end{array}$} & $\begin{array}{c}\text { Actor que la emplea } \\
\text { (individual o corporativo) }\end{array}$ & $\begin{array}{l}\text { Actor al que se dirige } \\
\text { (individual o corporativo) }\end{array}$ \\
\hline & & $\begin{array}{l}\text { Estado, sus actores coercitivos y } \\
\text { algunos funcionarios públicos }\end{array}$ & $\begin{array}{l}\text { Partidos políticos } \\
\text { Ciudadanía } \\
\text { Candidatos adversos a las mafias }\end{array}$ \\
\hline & & $\begin{array}{l}\text { Bandas armadas criminales, } \\
\text { organizaciones de tráfico } \\
\text { de drogas, de contrabando, } \\
\text { extorsión, lavado de dinero }\end{array}$ & $\begin{array}{l}\text { Clase política } \\
\text { Ciudadanía } \\
\text { Candidatos } \\
\text { Partidos políticos } \\
\text { Gobiernos locales }\end{array}$ \\
\hline & & $\begin{array}{l}\text { Partidos políticos y organismos } \\
\text { vinculados (sindicatos) }\end{array}$ & $\begin{array}{l}\text { Partidos políticos } \\
\text { Electores } \\
\text { Instituto Nacional Electoral (INE)/ } \\
\text { Organismo público local electoral } \\
\text { (OPLE) }\end{array}$ \\
\hline & \multirow[t]{2}{*}{$\begin{array}{l}\text { Acciones violentas que } \\
\text { dañan los derechos de los } \\
\text { ciudadanos }\end{array}$} & \multicolumn{2}{|c|}{$\begin{array}{l}\text { - Compra de voto, acarreo o coacción al votante } \\
\text { - Uso de programas sociales con fines electorales } \\
\text { - Obstaculizar el voto } \\
\text { - Falsificar documentos } \\
\text { - Proselitismo en fechas prohibidas } \\
\text { - Falsear o retener credenciales de elector } \\
\text { - Lavado de dinero } \\
\text { - Corrupción } \\
\text { - Uso ilícito de recursos } \\
\text { - Proselitismo prohibido }\end{array}$} \\
\hline & & \multicolumn{2}{|c|}{$\begin{array}{l}\text { - Acciones de dudoso estatus, como clientelismo político, que vulneran la } \\
\text { igualdad y libertad del votante } \\
\text { - Pertenencia a alguna agrupación política que influye ilegítimamente } \\
\text { en el ánimo del elector (facciones de partidos o pandillas; sindicatos } \\
\text { como el Sindicato Nacional de Trabajadores de la Educación, sNTE) }\end{array}$} \\
\hline
\end{tabular}

Fuente: Elaboración propia. 
equidad de género, 17 personas pretendieron registrarse para alcaldes como transgénero (muxe), aprovechando la oportunidad de las nuevas reglas de equidad de género (Zermeño, 2018). El Instituto Electoral de Oaxaca canceló su registro. ${ }^{8}$ Durante el periodo de observación de las campañas encontramos otros incidentes que pueden estar asociados con violencia basada en el género; sin embargo, no están documentados por la prensa o, incluso, son negados. Lo trascendente es que este proceso electoral hizo públicas una serie de conductas de acoso, agresión, intimidación hacia mujeres, quienes pretendían o esperaban competir por algún cargo electoral, pero se los impidieron hombres, ya sea familiares, autoridades locales o jefes de los partidos a los que estaban asociadas, por el hecho de ser mujeres (en Puebla, las candidatas Lourdes Martínez, Alma Salinas y Anita Reyes recibieron amenazas de muerte para que renunciaran a sus candidaturas [Llorame, 2018]). Desafortunadamente no hay espacio para tratar estos acontecimientos en el artículo, pero es importante reiterar que en los comicios de 2018 el debate por la equidad de género mostró varias dimensiones de vP que habían estado escondidas bajo el control masculino de la política.

La búsqueda realizada registró un total de 481 eventos entre 2012 y 2018; sin embargo, los actos transgresivos se elevan a 502 debido a que en varias ocasiones tuvo lugar más de una acción violenta y/o delito electoral en un mismo evento. El año 2018 concentra la mayoría de los casos entre otras cosas por la magnitud del proceso electoral. La tendencia de estos años marca que las agresiones van al alza, lo cual confirma nuestro argumento de que la vp sigue siendo un comportamiento concurrente en nuestras elecciones.

El cuadro 2 muestra los registros de las agresiones durante los últimos siete procesos electorales, tres de ellos con elecciones a la Presidencia y al Congreso de la Unión. Dentro de ese repertorio destacan los asesinatos, las amenazas y las agresiones, que son las acciones más recurrentes para influir en las elecciones.

De los casos registrados, 2018 concentra $76.09 \%$ (de un total de 481 desde 2012); el reporte muestra con nitidez que los asesinatos ocupan la mayor cantidad de eventos (38.25\%), contra las amenazas (19.39\%), los atentados (6.28\%) y el secuestro (4.37\%). Es probable que la concentración en 2018 se explique por la cantidad de puestos públicos en disputa y a que el tema fue mucho más visible, tal vez porque ese año la prensa fue más sensible a estas conductas. Debe anotarse que la mayoría de los puestos en la contienda eran estatales y municipales. Es allí donde se aglutinan las agresiones. Asimismo, hay más eventos violentos en años de elecciones locales, que en aquellas donde son sólo federales o simultáneas (con menor cantidad, pero en el mismo sentido en 2013, 2014, 2016 y 2017 contra 2012 y 2015). Por ejemplo, en 2012

Cuadro 2

Eventos delictivos por año, 2012-2018

\begin{tabular}{|c|c|c|c|c|c|c|c|c|}
\hline Tipo de agresión & 2012 & 2013 & 2014 & 2015 & 2016 & 2017 & 2018 & Total por delito \\
\hline Amenazas & 0 & 0 & 0 & 3 & 0 & $\mathrm{O}$ & 71 & 74 \\
\hline Robo & 0 & 1 & 1 & 0 & $\mathrm{O}$ & 0 & 7 & 9 \\
\hline Asesinato & 5 & 18 & 9 & 16 & 7 & 32 & 140 & 227 \\
\hline Atentado & 0 & 4 & 1 & 9 & 1 & 0 & 23 & 38 \\
\hline Secuestro & 0 & 3 & 1 & 3 & 0 & $\mathrm{O}$ & 16 & 23 \\
\hline Vandalismo & 0 & 0 & 0 & 1 & $\mathrm{O}$ & 0 & 16 & 17 \\
\hline $\begin{array}{l}\text { Violencia política } \\
\text { basada en el género* }\end{array}$ & 0 & 0 & 0 & 0 & 0 & 0 & 26 & 26 \\
\hline Agresiones* & 0 & 0 & 0 & 0 & 0 & 0 & 65 & 65 \\
\hline Extorsión* & 0 & 0 & 0 & 0 & 0 & 0 & 2 & 2 \\
\hline Total por años & 5 & 26 & 12 & 32 & 8 & 32 & 366 & 481 \\
\hline
\end{tabular}

* Categorías agregadas para las elecciones de 2018, por tal motivo no se cuenta con los datos de 2012 a 2017.

Fuente: Elaboración propia con base en datos de prensa, estudios, análisis y documentos públicos compilados para el proyecto de observación electoral INE-IIDH-CAPEL, 2018. Base actualizada al 3 de enero de 2019.

8 Cabe mencionar que todas las coaliciones de partidos procuraron registrar alguno de estos candidatos transgénero. 
hubo 2127 cargos de elección popular (629 federales); en cambio en 2018 estuvieron en disputa 2787 cargos locales (y los mismos 629 federales) (INE, 2018). En este sentido era de esperarse una mayor competencia y más casos de violencia; no obstante, divididos entre el número de cargos, son menos. Además, los eventos violentos ocurridos en 2018 son la gran mayoría de la base de datos.

A pesar de la limitada información de las notas periodísticas, fue posible identificar algunas características de las víctimas, así como ciertos patrones de ocurrencia que dan cuenta de manera más precisa sobre cómo se ejecutaron estos sucesos. Respecto del perfil de las víctimas se logró distinguir tres rasgos: sexo, cargo y afiliación partidista.

La tendencia general estuvo dirigida hacia una mayoría de hombres. En el cuadro 3 se muestra que $57.1 \%$ de las víctimas fueron hombres y $23.5 \% \mathrm{mu}-$ jeres, aun cuando en materia de violencia de género la gran mayoría fue de mujeres (24 de 26); empero, es relevante considerar que $19.4 \%$ de los registros carece de información suficiente.

Los datos referentes al cargo de las víctimas, contenidos en el cuadro 4, exponen cómo las diferentes clases de agresiones estuvieron orientadas a varios tipos de personas. Destacan en primer lugar los candidatos a alcaldes ( $17.7 \%$ ); luego, militantes de partidos ( $16.1 \%$ ); le siguen candidatos a diputado estatal (7.3\%), fun- cionarios de partido (6.8\%), presidentes municipales $(4.6 \%)$ y luego ciudadanos y funcionarios públicos de prácticamente todos los niveles, así como personas cuyas actividades se encuentran estrechamente ligadas a cuestiones político-electorales. Es esencial reiterar que la mayoría de las agresiones recayeron en personas responsables de cargos locales. Del total, $40 \%$ eran candidatos y $3 \%$ más funcionarios electos.

Con base en lo anterior, pudimos confirmar una primera hipótesis de trabajo: la violencia político-electoral se genera como consecuencia de disputas en el ámbito local.

Desde otra perspectiva, lo presentado en el cuadro 4 abre una serie de cuestionamientos de orden teórico-metodológico en cuanto al análisis de la violencia político-electoral. El listado de cargos de víctimas contiene candidatos, funcionarios, exfuncionarios e incluso ciudadanos. Una agresión hacia un candidato genera pocas dudas acerca de su clasificación como un hecho de violencia político-electoral; sin embargo, siempre quedará la posibilidad de que haya tenido una motivación distinta a la política. En los demás casos la dificultad de catalogar la agresión como violencia político-electoral aumenta. Con la información disponible, hallamos que en muchos sucesos las otras víctimas acompañaban a los candidatos en actos de campaña. ${ }^{9}$

Otro interrogante surge al analizar la adscripción partidista de las víctimas. El partido que acumuló

Cuadro 3

Acciones violentas según sexo de la víctima

\begin{tabular}{|c|c|c|c|c|}
\hline & Sin datos & Hombre & Mujer & Total \\
\hline Asesinato & 6 & 115 & 19 & 140 \\
\hline Amenazas & 13 & 32 & 26 & 71 \\
\hline Agresiones & 33 & 24 & 8 & 65 \\
\hline Violencia política basada en el género & 2 & $\mathrm{O}$ & 24 & 26 \\
\hline Atentado & 3 & 18 & 2 & 23 \\
\hline Secuestro & 3 & 8 & 5 & 16 \\
\hline Vandalismo & 7 & 8 & 1 & 16 \\
\hline Robo & 3 & 3 & 1 & 7 \\
\hline Extorsión & 1 & 1 & 0 & 2 \\
\hline Total & 71 & 209 & 86 & 366 \\
\hline Porcentajes & $19.4 \%$ & $57.1 \%$ & $23.5 \%$ & $100 \%$ \\
\hline
\end{tabular}

Fuente: Elaboración propia con base en datos de prensa, estudios, análisis y documentos públicos compilados para el proyecto de observación electoral INE-IIDH-CAPEL, 2018. Base actualizada al 3 de enero de 2019.

9 Merece la pena hacer notar que en 23 de los casos reportados no se dispuso de pormenores para afirmar que las agresiones que padecieron los "no candidatos" estaban ligadas al proceso electoral; por ahora, no logramos determinar si en estos incidentes fueron mecanismos de intimidación o coacción los que afectaron el curso de las campañas y, por ende, de las elecciones. 
Cuadro 4

Violencia político-electoral según cargo de la víctima

\begin{tabular}{|c|c|c|c|c|c|c|c|c|}
\hline & Asesinato & Atentado & Secuestro & Agresiones & $\begin{array}{c}\text { Violencia } \\
\text { política basada } \\
\text { en el género }\end{array}$ & Otros* & Total & $\%$ \\
\hline Candidato a alcalde & 7 & 8 & 2 & 4 & 9 & 35 & 65 & 17.76 \\
\hline Militante de partido & 24 & 6 & 3 & 15 & 1 & 10 & 59 & 16.12 \\
\hline $\begin{array}{l}\text { Candidato a } \\
\text { diputado local }\end{array}$ & 4 & 1 & & 4 & 2 & 16 & 27 & 7.38 \\
\hline Funcionario de partido & 20 & & 1 & 1 & 2 & 1 & 25 & 6.83 \\
\hline Presidente municipal & 12 & & 3 & & & 2 & 17 & 4.64 \\
\hline Ciudadano & 7 & & 2 & 3 & & 3 & 15 & 4.10 \\
\hline Otro político & 8 & & 1 & 3 & & 2 & 14 & 3.83 \\
\hline Precandidato & 9 & 1 & & 1 & & 0 & 11 & 3.01 \\
\hline $\begin{array}{l}\text { Candidato a regidor, } \\
\text { síndico o concejal }\end{array}$ & 6 & & & & 1 & 4 & 11 & 3.01 \\
\hline Exfuncionario & 10 & & 1 & & & 0 & 11 & 3.01 \\
\hline $\begin{array}{l}\text { Candidato a } \\
\text { diputado federal }\end{array}$ & 1 & 1 & & 2 & 3 & 3 & 10 & 2.73 \\
\hline Funcionario local & 7 & 1 & & 1 & & 0 & 9 & 2.46 \\
\hline Familiar de político & 7 & & & & & 0 & 7 & 1.91 \\
\hline Candidato a senador & & & & 1 & 2 & 3 & 6 & 1.64 \\
\hline Funcionario electoral & 2 & & & 1 & & 1 & 4 & 1.09 \\
\hline $\begin{array}{l}\text { Funcionario electo } \\
\text { en el ejercicio } 2018\end{array}$ & 2 & & & 1 & & 0 & 3 & 0.82 \\
\hline Candidato a gobernador & & & & & 2 & 0 & 2 & 0.55 \\
\hline Candidato a presidente & & & & 1 & & 1 & 2 & 0.55 \\
\hline Activista & 1 & 1 & & & & 0 & 2 & 0.55 \\
\hline Funcionario federal & 1 & & & & 1 & 0 & 2 & 0.55 \\
\hline Diputado local & 1 & & & & & 1 & 2 & 0.55 \\
\hline Eclesiástico & & & & & & 1 & 1 & 0.27 \\
\hline Prensa & 1 & & & & & 0 & 1 & 0.27 \\
\hline Diputado federal & & 1 & & & & 0 & 1 & 0.27 \\
\hline Sin dato & 10 & 3 & 3 & 27 & 3 & 13 & 59 & 16.12 \\
\hline Total & 140 & 23 & 16 & 65 & 26 & 96 & 366 & 100.00 \\
\hline
\end{tabular}

* Extorsión, robo, vandalismo y amenazas.

Fuente: Elaboración propia con base en datos de prensa, estudios, análisis y documentos públicos compilados para el proyecto de observación electoral INE-IIDH-CAPEL, 2018. Base actualizada al 3 de enero de 2019. 
mayor cantidad fue Movimiento de Regeneración Nacional (Morena), con $27.6 \%$ de los casos registrados; se trata de un partido emergente en los procesos y que podría haber agrupado agresiones que en realidad iban dirigidas hacia candidatos "originarios" de otros partidos (véase cuadro 5). Lo sigue el PRI, con 16.9\% y el Partido de la Revolución Democrática (PRD) con $16.4 \%$, así que los tres partidos acumulan más de la mitad de las víctimas. Dicha información resulta relevante si se toma en cuenta que Morena fue el partido con mayor éxito en el actual proceso electoral. El hecho de que las agresiones se concentren en ese partido fortalece la hipótesis de que la violencia político-electoral puede ser también explicada como pugnas interpartidistas, es decir, por confrontaciones entre grupos políticos con visiones e intereses antagónicos, y por la emergencia de un partido que rompió el statu quo. Morena enfrentó muchos retos y disputas entre partidos de todo el espectro electoral, así como pleitos locales. Por otro lado, debe destacarse que, si bien fue objeto de un mayor número de amenazas y agresiones, el PRI y el PRD sumaron la mayoría de las bajas por asesinatos (59).

Los datos ponen de manifiesto que la violencia afectó a todos los partidos porque perdieron algunos de sus integrantes en un homicidio; también ocurrió que se renunciara a la candidatura después de sufrir una agresión o que hayan sido derrotados. El PRI, el PRD y Morena aglutinan poco más de 50\% de los casos.

Con base en lo expuesto, puede proponerse que los homicidios del PRI, del Partido Acción Nacional (PAN), del PRD y Morena podrían relacionarse sobre todo con posibles pugnas intrapartido, Ahora bien, por lo que toca al PRD y a Morena sería factible también proponer que la causa de la violencia se vincula a los conflictos entre partidos y a la intervención de algún actor proclive a quebrantar la ley, como un cacique o un dirigente de alguna organización delictiva armada. Por la naturaleza de los incidentes y el tamaño de la muestra (54 casos) los resultados no pueden someterse a pruebas estadísticas sólidas. Para resolver esta carencia y analizar las posibles dinámicas violentas inter e intrapartidistas se consideraron únicamente los casos de violencia homicida (en 2018) y donde se contaba con información acerca de la adscripción partidista de la víctima.

Derivado de lo anterior, seleccionamos los tres partidos políticos con mayor número de homicidios registrados y verificamos si las víctimas eran de un partido distinto del que gobernaba la entidad, es decir, si se le puede atribuir a ese hecho que ocurrió en un contexto de oposición (véase cuadro 7).

Cuadro 5

Acciones violentas según partido de la víctima

\begin{tabular}{|c|c|c|c|c|c|c|c|c|c|c|c|c|c|c|c|}
\hline & $\begin{array}{c}\text { Sin } \\
\text { info. }\end{array}$ & INE & $\begin{array}{c}\text { Indepen- } \\
\text { diente }\end{array}$ & MC & Morena & NA & PAN & PES & PRD & PRI & PT & PVEM & $\begin{array}{c}\text { Partido } \\
\text { local }\end{array}$ & Total & $\begin{array}{c}\% \text { del } \\
\text { total }\end{array}$ \\
\hline Asesinato & 20 & 1 & 1 & 6 & 23 & 1 & 10 & 4 & 27 & 32 & 7 & 6 & 2 & 140 & 38.25 \\
\hline Amenazas & 7 & & & 2 & 29 & 1 & 3 & & 11 & 13 & 2 & 1 & 2 & 71 & 19.40 \\
\hline Agresiones & 8 & & 4 & 2 & 31 & & 7 & 1 & 5 & 5 & 1 & 1 & & 65 & 17.76 \\
\hline $\begin{array}{l}\text { Violencia } \\
\text { política } \\
\text { basada en } \\
\text { el género }\end{array}$ & 1 & & & 2 & 7 & & 4 & & 6 & 2 & 2 & 2 & & 26 & 7.10 \\
\hline Atentado & 1 & & & 1 & 6 & & 3 & 1 & 6 & 3 & & 1 & 1 & 23 & 6.28 \\
\hline Secuestro & 4 & & 1 & 1 & 1 & & 2 & & 3 & 3 & 1 & & & 16 & 4.37 \\
\hline Vandalismo & 6 & & & & 4 & & 3 & & 2 & 1 & & & & 16 & 4.37 \\
\hline Robo & 2 & 1 & & & & & 2 & & & 2 & & & & 7 & 1.91 \\
\hline Extorsión & & & & & & & 1 & & & 1 & & & & 2 & 0.55 \\
\hline Total & 49 & 2 & 6 & 14 & 101 & 2 & 35 & 6 & 60 & 62 & 13 & 11 & 5 & 366 & 100.00 \\
\hline $\begin{array}{l}\% \text { por } \\
\text { partido }\end{array}$ & 13.39 & 0.55 & 1.64 & 3.83 & 27.60 & 0.55 & 9.56 & 1.64 & 16.39 & 16.94 & 3.55 & 3.01 & 1.37 & 100 & \\
\hline
\end{tabular}

Fuente: Elaboración propia con base en datos de prensa, estudios, análisis y documentos públicos compilados para el proyecto de observación electoral INE-IIDH-CAPEL, 2018. Base actualizada al 3 de enero de 2019. 


\begin{tabular}{lc}
\multicolumn{1}{c}{ Cuadro 6 } & \\
\hline \multicolumn{1}{c}{ Partido } & Homicidios \\
\hline Partido Revolucionario Institucional (PRI) & 32 \\
Partido de la Revolución Democrática (PRD) & 27 \\
Movimiento de Regeneración Nacional (Morena) & 23 \\
Paritdo Acción Nacional (PAN) & 10 \\
Movimiento Ciudadano (MC) & 6 \\
Partido del Trabajo (PT) & 7 \\
Partido Verde Ecologista de México (PVEM) & 6 \\
Partido Encuentro Social (PES) & 4 \\
Partido local & 2 \\
Instituto Nacional Electoral (INE) & 1 \\
Independiente & 1 \\
Nueva Alianza (NA) & 1 \\
Sin información & 1 \\
\hline Total & $\mathbf{1 4 0}$ \\
\hline
\end{tabular}

Fuente: Elaboración propia con base en datos de prensa, estudios, análisis y documentos públicos compilados para el proyecto de observación electoral INE-IIDH-CAPEL, 2018. Base actualizada al 3 de enero de 2019.

Tenemos suficientes cifras para sostener nuestra hipótesis de que la violencia homicida se dirige de un modo particular cuando el candidato es de oposición (82 de 140 casos). De los afiliados al PRD, 85.19\% de los fenecidos eran de oposición a la filiación partidaria de la gubernatura en donde ocurrieron los hechos. Le siguen los miembros de Morena (78.26\%); era de esperarse que enfrentara muchos conflictos como partido emergente, $y$, finalmente el PRI, con $37.5 \%$ de casos. Los partidos de izquierda que presentaron coaliciones fueron los más afectados, pero los datos no nos permiten por ahora esclarecer si la figura de las coaliciones estuvo asociada con cierto tipo de ve.

Dentro de los números presentados en el cuadro 7 fue posible identificar en qué municipio tuvieron lugar los homicidios y señalar de manera más precisa dónde sucedieron éstos. Al revisar con detalle nuestros registros pudimos establecer que existen notables variaciones en los patrones de ocurrencia de los delitos. A continuación presentamos algunos ejemplos: Chilapa de Álvarez, en Guerrero, aparece como el municipio que suma la mayor cantidad de homicidios (dos del PRI; dos del PRD y uno de Morena), los cuales ocurrieron de manera independiente. Con igual número de homicidios está el municipio San Vicente Coatlán, en Oaxaca, pero todos ellos forman parte de una emboscada en contra de Emigdio López Avendaño, candidato de Morena (es decir, fueron perpetrados contra miembros de una misma organización política a diferencia de lo que pasó en Chilapa de Álvarez).

\section{Cuadro 7 \\ Asesinatos cuando la víctima es de un partido de oposición al partido gobernante en entidades federativas}

\begin{tabular}{lccc}
\hline Partido & Eventos por partido & Número de asesinatos siendo oposición & \% de asesinatos siendo oposición \\
\hline PRI & 32 & 12 & 37.50 \\
PRD & 27 & 23 & 85.19 \\
Morena & 23 & 18 & 78.26 \\
\hline
\end{tabular}

Fuente: Elaboración propia con base en datos de prensa, estudios, análisis y documentos públicos compilados para el proyecto de observación electoral INE-IIDH-CAPEL, 2018. Base actualizada al 3 de enero de 2019. 


\section{Resultados y conclusión}

Este artículo examina las elecciones de 2018 y estudia las distintas modalidades y probables causas que explican la producción de ve. Entre los interrogantes que guiaron el trabajo para explicar este tipo de violencia estaban aquellos asociados a la competencia política, a la fragmentación partidaria, al papel de las autoridades locales en la generación de la misma (o en su omisión), a la importancia del cargo y la escala de éste, a ciertos incentivos vinculados a las leyes y la debilidad de las instituciones electorales (impunidad), y a la presencia de organizaciones criminales.

Para responder a todo lo anterior, planteamos un conjunto de hipótesis y las contrastamos con la base de datos generada para el estudio. La primera postulaba que la competencia entre partidos y candidatos genera la vE; la segunda es que la escala y el cargo o "puesto" en competencia (su jerarquía local o federal) explica la vE; la tercera vinculaba los conflictos locales y la polarización entre ellos; y la cuarta asociaba la vE con la presencia de delincuentes.

La ve es un fenómeno que persiste en los comicios del país y ha ido en aumento desde 2012, contrario a lo que se esperaría del proceso de democratización. Además, en 2018 se registraron 366 casos de acciones violentas; incluidos 140 asesinatos (de un total de 227 en el periodo 2012-2018); 71 amenazas y 45 agresiones a candidatos, funcionarios militantes de partido o ciudadanos, sobre todo varones. La mayoría de los hechos están concentrados en el ámbito local (contra candidatos a alcaldías, a diputaciones estatales y presidentes municipales) y en funcionarios y militantes de partido donde se celebraban elecciones concurrentes de gobernador, de congreso estatal y de presidente de la república. En sitios con elecciones concurrentes se dio la mayor cantidad de asesinatos. En cuanto a los partidos políticos, Morena fue el que sufrió un mayor número de actos de violencia, con 101 registros, seguido del PRI con 62 y el PRD con 60 . Empero, el PRI fue el que más homicidios experimentó (32 casos), seguido del PRD con 27 y Morena con 23.

Otra conclusión sostenible del estudio es que la creciente situación criminal en México está afectando las elecciones locales y nacionales. En algunos casos ocurre como un factor contextual, pero en otros es la causa de disputas y de numerosas actividades ilícitas que han alterado los comicios y la integración de gobiernos.

En síntesis, propusimos en primer lugar que es la competencia entre partidos la que produce violencia contra la oposición; en segundo lugar, que la afiliación partidaria también cuenta al hablar de asesinatos.
Mostramos que Morena fue el partido más afectado y casi siempre era partido emergente-opositor. Lo mismo sucedía con varios casos del PRD. Los asesinatos que afectaron a sus militantes o candidatos (en más de ocho de cada diez) ocurrieron mientras competían como oposición y no como partido en el gobierno. En cambio, las agresiones contra el PRI suelen responder a conflictos en su interior (o entre la élite local). Finalmente, las entidades federativas con más actos violentos fueron Puebla con 60, Guerrero con 52, la Ciudad de México con 33, Oaxaca con 26 y el Estado de México con 24. Respecto a los homicidios, Guerrero fue el estado más afectado, con un total de 26, Oaxaca y Puebla con 16 cada uno, y Michoacán con diez.

Las localidades y el contexto también importan. Con la intención de proporcionar un panorama de la distribución de la violencia político-electoral en el territorio nacional, integramos cuatro grupos de entidades donde ocurrió la mayoría de los eventos en el año 2018. Diez entidades concentran $80 \%$ de los hechos de violencia contabilizados. En el primer grupo están Puebla (la entidad con la posición más alta), seguida de Guerrero y la Ciudad de México. Cabe anotar que en Puebla y en la capital del país se celebraron elecciones de poder ejecutivo estatal; el segundo grupo lo constituyen Oaxaca y el Estado de México, que acumulan más de 20 casos cada una. El tercer grupo lo conforman Michoacán, Chiapas, Chihuahua, Jalisco y San Luis Potosí, que cuentan con más de diez registros de hechos violentos. En el cuarto grupo, y en sentido opuesto destacan Querétaro, Baja California Sur y Campeche, estados donde no se registraron hechos violentos, no porque no hayan ocurrido, sino porque ni la prensa ni los partidos ni las autoridades electorales los publicaron. Las entidades que aparecen con más incidentes de violencia político-electoral son en su mayoría las que históricamente se han caracterizado por protagonizar conflictos sociales y pugnas políticas.

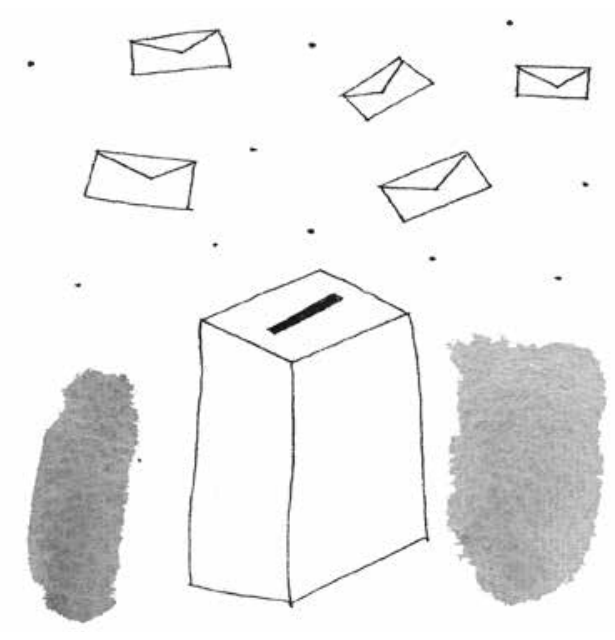


La identificación de atributos en los homicidios como los antes expuestos puede ser la base para construir una tipología de homicidios políticos en el futuro. A fin de profundizar la reflexión sobre estas tendencias nos es dable argumentar que la polarización y la fragmentación partidaria pueden generar la violencia, sobre todo cuando la disputa por los votos es muy cerrada, competitiva y cuando los candidatos son de oposición y, además, cambian de afiliación partidaria.

Cabe preguntarse si los partidos que más incurren en delitos electorales son aquellos con mayor fuerza en el sistema político y, por ende, con estructuras y dinámicas ancladas territorialmente que les permiten desarrollar diversas prácticas irregulares. Esto podría explicar en particular los actos contra Morena.

Para terminar esta interpretación, dos hechos dominaron el proceso electoral de 2018. En primer lugar está el ambiente de conflicto con el que arrancaron las campañas, que fue tornándose favorable hacia el triunfo de Morena, cuyo candidato presidencial logró un arrastre muy claro de sus candidatos en varios estados y localidades (como en Veracruz y la Ciudad de México, pero no en Puebla). En segundo lugar está la creciente presencia de conflictos, enfrentamientos y múltiples modalidades de violencia política, electoral y violencia basada en el género en los últimos años (podría argumentarse también que esta violencia es nueva frente a la tradicional violencia política del siglo $\mathrm{xx}$ ). En estas situaciones se puso de manifiesto que las normas electorales tenían una mínima influencia sobre dichas confrontaciones y que las autoridades electorales poco o nada lograron -ya fueran los organismos electorales, los jurisdiccionales o la fiscalía especial creada para investigar y perseguir estos delitos, la FEPADE-, todo lo cual alimentó la impunidad con que se realizaron estos delitos.

Por último, futuros trabajos podrán ahondar en las ideas propuestas respecto de si la violencia política y la electoral son consecuencia de la fragmentación del poder, de la debilidad de las fuerzas partidarias frente a otras formas de acción política y / o de la impunidad que impera en el país, dado que los agresores casi nunca pagan los costos de sus delitos y la pérdida y el daño no se corrigen. Todo esto nos hace preguntarnos: ¿Se está produciendo una época político-electoral más conflictiva? ¿La nueva élite es más contenciosa y más proclive a competencias poco civiles? Y, en cuanto a los electores, ¿qué papel han tenido en estos procesos?; ¿son espectadores pasivos de la violencia? Ya sea como súbditos de poderes públicos y otras formas de poder privado, lícito o no, en muchos casos se encuentran inermes frente a estos conflictos, en otros actúan atendiendo a incentivos clientelares o delictivos $\mathrm{y}$, de este modo, responden a gobiernos resultantes de estas transgresiones.

\section{Fuentes}

Arendt, Hannah

1970 On Violence, Harcourt Books, Nueva York.

Derrick, Marco

2009 Reducing Electoral Conflict: A Toolkit, Election Monitoring Network / Open Society Foundation, Cape Town < http: / / quaker.org/legacy/peacenetwork/Reducing_Electoral_Conflict_Toolkit. pdf $>$ [ 14 de mayo de 2018]

Fischer, JeFF

2002 Electoral Conflict and Violence. A Strategy for Study and Prevention, International Foundation for Electoral Systems (IFEs White Paper), Washington.

GaRduño, RoBERTO

y José AnTONIO Román

2003 "Amigos de Fox transfirió dinero a Fox Quesada como "pago de honorarios"”, en La Jornada, 10 de octubre <http: / /www.jornada.unam.mx/ $2003 / 10 / 10 / 008 n 1$ pol.php?printver $=0 \& f l y=>$ [ 10 de octubre de 2010].

GonzÁlez, Marcos

2019 "Elecciones en El Salvador: ¿qué papel juegan las pandillas en los comicios presidenciales del país centroamericano?", en BBC-Mundo, 1 o de febrero <https: / / www.bbc.com/mundo/ noticias-america-latina-47036556> [18 de marzo de 2019].

Guerrero, Eduardo

2014 "La dictadura criminal", en Nexos, 1 de abril <http: / /www.nexos.com.mx/?p=20026> [18 de marzo de 2019].

Gutiérrez, HÉctor

2018 "PRD también da tinacos, relojes y hasta laptops", en El Financiero, 9 de abril <https: / / www.elfinanciero.com.mx/nacional / prd tambien-da-tinacos-relojes-y-hasta-laptops $>$ [18 de marzo de 2019].

INE

2018 Elecciones $2018<\mathrm{https}$ //www.ine.mx/ voto-y-elecciones/elecciones-2018/> [19 de septiembre de 2018].

LloRAME, HÉCTOR

2018 "Ocho candidatas han sufrido violencia política en Puebla: Observatorio", en Ángulo 7, 23 de abril <https://www.angulo7.com $\mathrm{mx} / 2018 / 04 / 23$ /ocho-candidatas-sufridoviolencia-politica-puebla-observatorio/> [ 14 de mayo de 2019].

Martínez I Coma, Ferran,

PipPa NorRIS y RichaRd W. Frank

2015 "Integridad en las elecciones de América Latina 2012-2014", en América Latina Hoy, vol. 70, pp. 37-54.

MOCHTAK, Michal

2018 Electoral Violence in the Western Balkans. From Voting to Fighting and Back, Routledge, Nueva York.

MOLINAR, JUAN

1991 "Geografía electoral", en Carlos Martínez Assad (coord.), Balance y perspectivas de los estudios regionales en México, Universidad Nacional 
Autónoma de México-Centro de Investigaciones Interdisciplinarias en Humanidades/Porrúa, México, pp. 397-446.

MoOre, BARrington JR.

1996 La injusticia: bases sociales de la obediencia y la rebelión, Universidad Nacional Autónoma de México-Instituto de Investigaciones Sociales, México.

Moreno, Florentino

2009 "Violencia colectiva, violencia política, violencia social. Aproximaciones conceptuales", en Iñaki Markez, Alberto Fernández y Pau Pérez-Sales (coords.),Violenciay saludmental,AsociaciónEsNieburg, Harold pañola de Neuropsiquiatría, Madrid, pp. 19-36.

1969 Political Violence: The Behavioral Process, St. Martin's Press, Nueva York.

North, Douglass C., John Joseph Wallis

Y BARRY R. WINGAST

2009 Violence and Social Orders: A Conceptual Frameworkfor Understanding Recorded Human History, Cambridge University Press, Nueva York.

Ponce, Aldo

2014 Narcos, violencia y competitividad electoral a nivel municipal: evidencia del caso mexicano, Centro de Investigación y Docencia Económicas (Cuadernos de Trabajo 5), México.

Ponce, Aldo

2018 "Violence and Electoral Competition: Criminal Organizations and Municipal Candidates in Mexico", en Trends in Organized Crime, pp. $1-24$.

Pulido, Amalia

2017 "Violencia y comportamiento electoral: el caso del Estado de México", en Apuntes Electorales, núm. 56, junio, pp. 9-38.

Romero, Mauricio (ED.)

2007 Parapolítica. La ruta de la expansión paramilitary los acuerdos políticos, Corporación Nuevo Arco Iris, Bogotá
SCHMITT, CARL

1982 Teoría de la Constitución, Alianza Editorial, Madrid.

Sonnleitner, Willibald, Arturo Alvarado

y ARTuro SÁNCHez

2013 "La paradoja mexicana: de la evaluación de la calidad técnica de las elecciones de 2012 , al debate sobre la calidad del voto y a la cuestión de la legitimidad democrática", en Revista Mexicana de Derecho Electoral, Especial sobre Observación Electoral 2012, núm. 4, pp. 369. 392.

Wilkinson, STEVEN

2004 Votes and Violence. Electoral Competition and Ethnic Riots in India, Cambridge University Press, Cambridge.

ZERMEÑo, RuBÉn

2018 "Denuncian muxes a candidatos 'transexuales' impostores", en Reporte Índigo <https: / / www.reporteindigo.com/reporte/denuncianmuxes-a-candidatos-impostores / > [ 7 de mayo de 2018].

\section{Hemerografía principal}

El Universal <http: / /www.eluniversal.com.mx/> [5 de septiembre de 2017-19 de septiembre de 2018].

Excélsior <https: / / www.excelsior.com.mx/ > [5 de septiembre de 2017-19 de septiembre de 2018].

La Jornada <https: / /www.jornada.com.mx> [5 de septiembre de 2017-19 de septiembre de 2018].

Milenio <http://www.milenio.com/> [5 de septiembre de 2017-19 de septiembre de 2018].

Proceso <https: / /www.proceso.com.mx/> [5 de septiembre de 2017-19 de septiembre de 2018].

Reforma <https: / / www.reforma.com/ > [5 de septiembre de 2017-19 de septiembre de 2018].

Sin Embargo <http: / / www.sinembargo.mx/ > [5 de septiembre de 2017-19 de septiembre de 2018]. 